\section{Are implementation science advances and digital technology developments important in sports medicine? Sports Medicine Australia thinks so}

\author{
Jacqueline Tran, ${ }^{1}$ Caroline F Finch ${ }^{2}$
}

The rate of growth of scientific knowledge gains pace year-on-year. Over 20 million journal articles have been indexed in MEDLINE from 1947 to 2012, with the number of publications increasing by an average of $5.2 \%$ per year. ${ }^{1}$ So how might our global community of researchers, clinicians and practitioners pool our collective knowledge to effect improvement in clinical practice?

In this issue of BJSM, curated on behalf of Sports Medicine Australia (SMA), we explore the power of better understanding of intervention implementation and in embracing the new digital technologies. For several years, BJSM has had a major focus on implementation science developments and their applications. ${ }^{2}$ Rigorously controlled studies will always have their place in the literature, but as outlined previously by Finch $^{3}$ and Peters et al (see page 731), implementation research seeks to investigate: How can efficacious interventions work harmoniously within the dynamics of the real world? Hanson et al (see page 682) stress that research alone is not enough and that more connection with that real world is needed. One dynamic of our modern age is that of digital technology, providing new opportunities for researchers, clinicians and practitioners to test and implement interventions. Several articles in this issue demonstrate the application of big data analytics and sensor technology to conduct research and implement interventions in sports and exercise medicine. In addition, social media platforms now provide direct and collaborative ways to engage with athletes and clients. The potential to reach a global population is now, quite literally, at our fingertips.

\footnotetext{
${ }^{1}$ Centre for Exercise and Sports Science, Deakin University, Burwood, Victoria, Australia; ${ }^{2}$ Faculty of Health Sciences, Centre for Healthy and Safe Sport, Federation University Australia, Ballarat, Victoria, Australia

Correspondence to Jacqueline Tran, Centre for Exercise and Sports Science, Deakin University, 221 Burwood Highway, Burwood, VIC 3125, Australia; jac@jacquietran.com
}

\section{IMPLEMENTATION RESEARCH}

Conceptual thinking by Verhagen et al (see page 698), who propose an explicit knowledge transfer scheme, brings together scientific evidence and practical experience to inform the design and implementation of clinical and field-based interventions. Effective implementation of any strategy requires appropriate involvement of key stakeholders; in community sport, coaches can play a particularly influential role. As evidence of the growing prominence of implementation research, we feature two studies relating to the delivery and uptake of neuromuscular control exercise training programmes conducted in a community-level Australian football. One article shows how what players think about injury prevention needs to inform how such programmes are designed to be delivered (see page 702). The second describes how likely it is that players will attend training sessions where exercise programmes are delivered and then whether or not they do the exercises (see page 718). Finally, Cools et al (see page 692) summarise evidence about rehabilitation of scapular dyskinesis to inform clinical practice guidelines that apply from elite athletes to office workers.

\section{TECHNOLOGICAL ADVANCEMENTS IN SPORTS AND EXERCISE MEDICINE}

Several articles demonstrate how digital technologies can be used in research and practice. Progressive sensor technology offers novel ways to objectively monitor exercise adherence. Rathleff et al (see page 729) prescribed shoulder abduction exercises using elastic exercise bands with embedded stretch sensors, and found that clinicians could accurately interpret the sensor output to identify when the exercises were correctly performed. Finally, Verhagen et al (see page 680) supply fascinating insights into how BJSM uses a variety of social media platforms to promote cutting edge research and engage with its international audience.
The possibilities afforded by digital technology have exciting implications for sports medicine professionals, although Verhagen et al (see page 680) recommend that we proceed carefully as the technical possibilities outpace our current capacity to use these tools optimally. Similarly, caution is advised by Orchard et al (see page 677) on the use of imaging tests to diagnose sports-related pathologies, given recent landmark studies confirming the long-term health risks associated with exposure to ionising radiation. In response, Forster (see page 679) provides guidelines to help guide sports medicine clinicians when weighing up the risks and benefits of using imaging procedures.

\section{SPORTS INJURY PREVENTION}

The overarching goal of sports medicine is to utilise expertise to maintain athlete health and consequently improve performance. Cricket and Australian football, two of Australia's most popular sports, are featured in this issue. Hulin et al (see page 708) used mathematical modelling to explore impact of workloads on injury risk for elite fast bowlers, while Morton et al (see page 685) investigated low-back pain risk factors and treatment effectiveness for cricket players. In elite Australian football, hamstring strain injuries remain the most prevalent injury sustained and are associated with significant financial costs (see page 729). Simple diagnostic tests with predictive validity, such as the single leg bridge test described by Freckleton et al (see page 713), would be valuable for early assessment and ongoing monitoring of injury risk.

\section{SMA ENCOURAGES YOU TO 'BE ACTIVE'}

SMA is Australia's peak national umbrella body for sports medicine and sports science, and is Australia's peak advisory body on all medical and health issues for active people. With this unique responsibility, SMA plays an active role in bridging the gap between research and practice by coordinating the annual ASICS Australian Conference of Science and Medicine in Sport (ACSMS); in 2014, ACSMS forms part of the biennial be active symposium. We invite professionals across all sports science and sports medicine fields, from Australia and abroad, to join us in Canberra from October 15 to 18 for be active 2014. For more information including abstract submission details, keep an eye on our website: http://www.sma. org.au. 
SMA has steadily expanded its online presence to utilise the power of social media, in order to keep our members abreast of the latest research and to connect members to one another. To get in touch with SMA, leave a message on our Facebook page (http://www.facebook. com/sportsmedicineaustralia), or send a tweet to our Chief Executive Officer, Nello Marino (@SMACEO). As coeditors, we also welcome your feedback, so feel free to tweet us at @ CarolineFinch or @JacquieTran.
Contributors JT and CFF contributed to the writing and revision of this manuscript.

Br J Sports Med 2014;48:675-676.

Competing interests None.

Provenance and peer review Commissioned; internally peer reviewed.



To cite Tran J, Finch CF. Br J Sports Med 2014;48:675-676.

Accepted 8 February 2014

\section{doi:10.1136/bjsports-2014-093541}

\section{REFERENCES}

1 US National Library of Medicine 2013, 'MEDLINE $\circledast$ Citation Counts by Year of Publication'. http://www. nlm.nih.gov/bsd/medline_cit_counts_yr_pub.html (accessed 29 Jan 2014).

2 Finch CF. Implementation and dissemination research. The time has come! Br I Sports Med 2011;45:763-4.

3 Finch CF. No longer lost in translation-the art and science of sports injury prevention implementation research. Br J Sports Med 2011;45:1253-7. 